\title{
Treatment of Subacute Polyneuritis with Corticosteroids
}

\author{
M. J. NEWMAN and N. NELSON
}

SUMMARY: $A$ study of the course of 17 patients with subacute polyneuritis was undertaken. Ten were given corticosteroids. Assessment of time of turnaround, that is the beginning of clinical improvement, showed that some patients responded promptly to steroids whereas a few did not. A comparison of turnaround times between the treated and untreated cases shows a statistically significant effect of steroids in hastening the onset of recovery. This is not due to bias in selection of those for steroid treatment.

RÉSUMÉ: L'évolution clinique de 17 patients souffrant de polynévrite subaique fut étudiée. Dix patients ont reçu des corticostéroides. 'En analysant le moment du "revirement" de l'évolution clinique vers le mieux, on a pu constater que certains patients répondaient relativement rapidement aux stéroides, alors que d'autres étaient plus lents. La même analyse permet de conclure, en comparant les patients recevant ou ne recevant pas de traitement, que les stéroides favorisent de façon significative le début de l'amélioration, et que ceci n'est pas dû aux biais de sélection en faveur du traitement.

From the Manitoba Rehabilitation Hospital and the Departments of Medicine and Medical Statistics of the University of Manitoba.

Reprint requests to Dr. M. J. Newman, Department of Medicine, University of Manitoba, 753 McDermot Avenue, Winnipeg R3E 0T5 Canada.
After more than twenty years, the value of corticosteroid treatment in idiopathic polyneuritis (GuillainBarre syndrome) is still not established. Shy and McEachern published a report of three cases treated in 1951. In 1957 Graveson reported seven cases. In five of these he thought that there was a response to this drug. Heller and DeJong (1963) published a complete review of the world literature on the subject and came to no definite conclusion. Siegenthaler and Regli (1966) reviewed the continental literature, including 38 cases treated with steroids, and stated that "the treatment has no definite influence on this disease."

An opportunity to test the efficacy of corticosteroids was presented while studying patients transferred to the Manitoba Rehabilitation Hospital in the years 1963 to 1972 .

In patients with polyneuritis of acute onset and progression, steroids had generally been given, if at all, early in the course of the disease. As acute cases treated with steroids cannot be compared with controls which might well have a slower tempo, such cases were not included in a comparative analysis in this study. In idiopathic polyneuritis there appears to be a continuous spectrum of duration of disease. Figure 1 shows the number who have not reached turnaround (first recorded sustained improvement) at each day from onset in 52 cases admitted to the Rehabilitation Hospital. Owing to the provenance of the study, this group tends towards the less acute and more severe cases, but the probability of turnaround in each ten-day interval from onset seems to be more or less constant from 10-100 days. Prineas (1970) defined acute cases as those with a progressive phase of less than three weeks and subacute cases as those progressing for more than three weeks. In this study a comparison of the course of disease with and without steroids has been confined to Prineas' subacute category.

In a chronic disease with a natural tendency to recover, it is important to have some measurable criteria of the efficacy of treatment. Idiopathic polyneuritis, whether acute or subacute, is a condition which usually recovers. There are therefore four important dates in the course of the disease: onset, maximal disability, turnaround and recovery. The date of onset can usually be ascertained within a week from the patient's history, supplemented by that of the relatives. The date of maximum disability is assumed to be the last day on which deterioration is noted, and turnaround is the first day of sustained improvement. Wherever possible, these dates were determined by quantitative measurements of power in selected muscles, usually hand grip and quadriceps. Figures 2 and 3 show the type of response observed. Since many patients had reached maximum disability before transfer to the Rehabilitation Hospital, this date often had to be determined from the hospital chart which is much less reliable. The time of recovery is impossible to estimate with any accuracy because it is so gradual. Furthermore, clinical recovery may precede electrical and pathological recovery.

\section{THE SUBJECTS}

Seventeen patients who met the requirements of the study, were admitted to the Rehabilitation Hospital over the space of 10 years. All had a diagnosis of idiopathic polyneuritis or Guillain-Barre syndrome, using 
the criteria set out by Wiederholt, Mulder and Lambert (1964). All had severe or moderately severe, symmetrical, lower motor neuron weakness; all had subjective sensory loss, including loss of position sense in the toes. Eight had cranial nerve involvement, and one was sufficiently severe to require a period of assisted ventilation. Four were able to stand unsupported at the time of maximum disability. Nerve conduction tests were performed in 15 and were abnormal in all of these. Serial nerve conduction tests were done in 10 and a blink-reflex test (Kimura, 1971) in one. In the latter, slowing of conduction in both fifth and seventh cranial nerves was demonstrated. None was started on steroids until after admission. A search of hospital records revealed no other case of subacute idiopathic polyneuritis, apart from these 17, admitted during the ten years to any hospital in metropolitan Winnipeg, a city of 600,000 inhabitants.

There were ten males and seven females ranging in age from nine to

Figure 1 - A series of 52 patients with the diagnosis of Idiopathic Polyneuritis admitted to the Manitoba Rehabilitation Hospital over the space of ten years. This graph shows the number of patients who had not yet begun to show sustained improvement at each day after the onset of symptoms.

Figure 2 - The course of a 53-year-old male patient who showed a rapid increase in strength starting 2 days after steroid treatment was begun and 84 days after the onset of his symptoms. Measurements of strength on the ordinate, days of illness on the abscissa.

Figure 3 - The course of a 58-year-old patient who showed gradual increase of strength starting 10 days after treatment with corticosteroids was begun and 161 days after the onset of his symptoms.
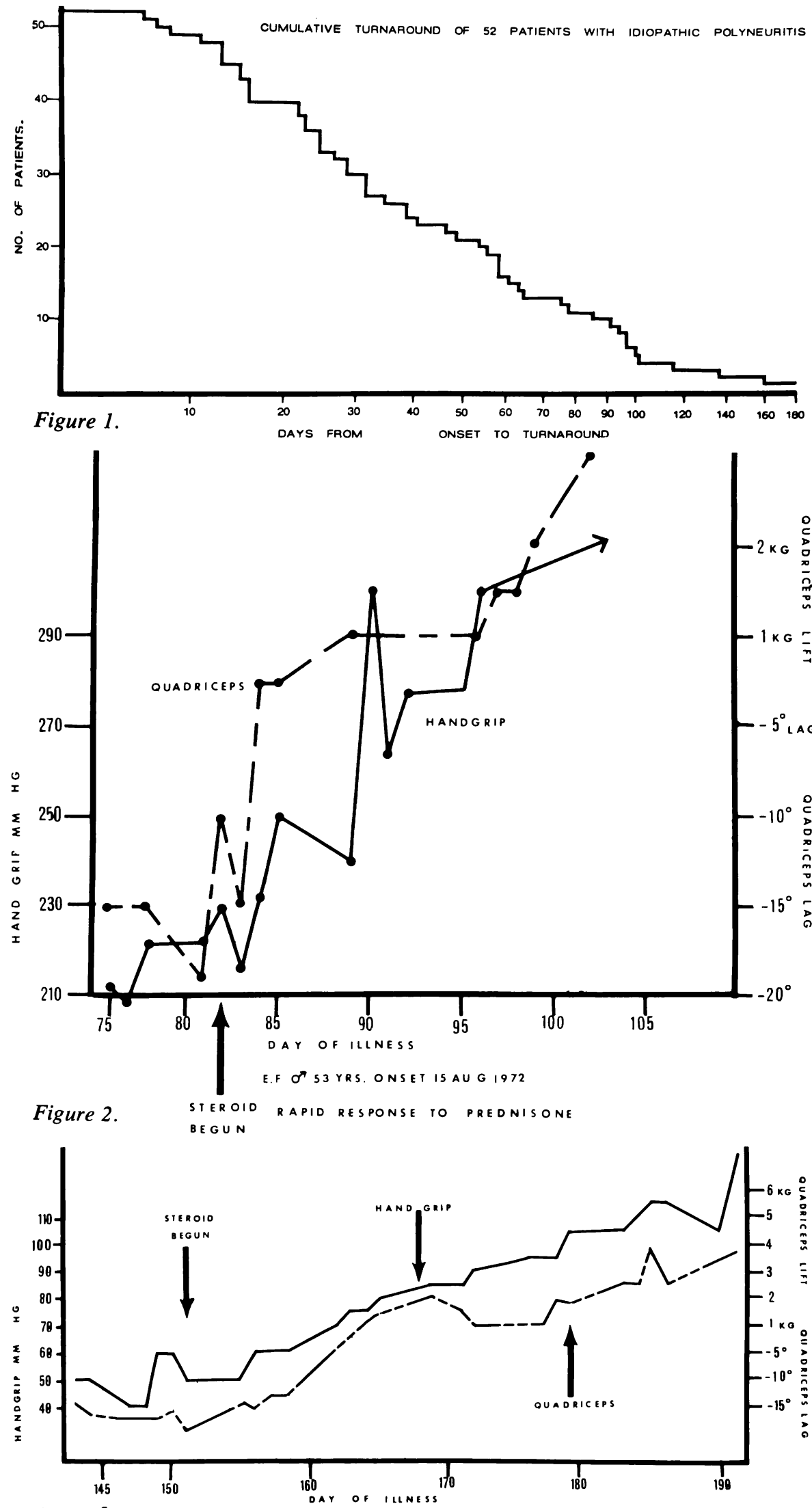

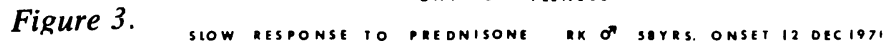


seventy years old. Table 1 displays the important features of each case. One patient was started on corticosteroids 48 hours after transfer because of persisting ventilatory insufficiency. The others were observed for a period before steroids were considered. If turnaround did not occur during this period of observation, corticosteroids in a dose of 20 to $30 \mathrm{mgms}$. per day were started, continued for a duration of from one to twenty weeks (average 9 weeks). A number of patients turned around during the observation period and were not given steroids. All had a similar physiotherapy program consisting of assisted active movements and maintenance of range of motion of all joints up to the time of turnaround. When recovery was underway, increasingly vigorous exercise against resistance was prescribed.

\section{RESULTS}

Table 4 shows 8 of the 10 patients given steroids turned around in less than 10 days from the start of the drug. In two of them, turnaround occurred within 24 hours, and in these there is prima facie evidence that the drug had some influence on the course of recovery. When the disease has already extended for several weeks or months without recovery, a longer interval could well be significant. To test this possibility, each patient starting on steroid was considered as a selection, hopefully a random selection from all the patients available for

TABLE 1

Summary of patients with Subacute Polyneuritis

$\begin{array}{ccccc}\text { Age and Sex } & \begin{array}{c}\text { Deterioration } \\ \text { ceased }\end{array} & \begin{array}{c}\text { Day of illness } \\ \text { steroid } \\ \text { started }\end{array} & \begin{array}{c}\text { Improvement } \\ \text { commenced }\end{array} & \text { Severity } \\ 47 \mathrm{M} & 63 & 64 & 65 & 3 \\ 29 \mathrm{M} & 28 & - & 97 & 2 \\ 37 \mathrm{~F} & 35 & 55 & 39 & 2 \\ 59 \mathrm{~F} & 50 & 58 & 64 & 2 \\ 35 \mathrm{~F} & 56 & 24 & 61 & 2 \\ 49 \mathrm{~F} & 28 & 130 & 32 & 1 \\ 62 \mathrm{M} & 28 & - & 137 & 2 \\ 68 \mathrm{M} & 30 & 77 & 47 & 2 \\ 70 \mathrm{M} & 60 & 83 & 78 & 2 \\ 39 \mathrm{M} & 35 & - & 102 & 2 \\ 14 \mathrm{M} & 30 & - & 92 & 1 \\ 40 \mathrm{~F} & 72 & - & 97 & 1 \\ 54 \mathrm{~F} & 60 & - & 76 & 1 \\ 45 \mathrm{~F} & 105 & 151 & 116 & 2 \\ 9 \mathrm{M} & 28 & 84 & 161 & 2 \\ 58 \mathrm{M} & 112 & & 86 & \\ 53 \mathrm{M} & 53 & & & \end{array}$

Severity 3 respiratory failure

2 unable to stand

1 able to stand unassisted

TABLE 4

Comparison of the interval remaining before turnaround at various áurations of illness in patients not yet given steroids and the interval between the start of treatment and turnaround in those given steroids.

\begin{tabular}{|c|c|c|c|c|c|c|c|c|c|}
\hline \multirow[b]{2}{*}{ Day of illness } & \multirow[b]{2}{*}{$\begin{array}{c}0-4 \\
\text { days }\end{array}$} & \multicolumn{7}{|c|}{$\begin{array}{c}\text { Number of cases available for steroid who began to improve at } \\
\text { various intervals after the day in column } 1 .\end{array}$} & \multirow[b]{2}{*}{$\begin{array}{r}50+ \\
\text { days }\end{array}$} \\
\hline & & $\begin{array}{c}5-9 \\
\text { days }\end{array}$ & $\begin{array}{l}10-14 \\
\text { days }\end{array}$ & $\begin{array}{l}15-19 \\
\text { days }\end{array}$ & $\begin{array}{l}20-24 \\
\text { days }\end{array}$ & $\begin{array}{c}25-29 \\
\text { days }\end{array}$ & $\begin{array}{l}30-39 \\
\text { days }\end{array}$ & $\begin{array}{l}40-49 \\
\text { days }\end{array}$ & \\
\hline $\begin{array}{l}20 \text { days } \\
50 \text { days } \\
60 \text { days } \\
70 \text { days }\end{array}$ & $\begin{array}{l}0 \\
0 \\
0 \\
0\end{array}$ & $\begin{array}{l}0 \\
1 \\
1 \\
2\end{array}$ & $\begin{array}{l}1 \\
2 \\
0 \\
0\end{array}$ & $\begin{array}{l}1 \\
1 \\
2 \\
1\end{array}$ & $\begin{array}{l}0 \\
0 \\
0 \\
1\end{array}$ & $\begin{array}{l}1 \\
2 \\
1 \\
2\end{array}$ & $\begin{array}{l}1 \\
1 \\
3 \\
1\end{array}$ & $\begin{array}{l}3 \\
3 \\
1 \\
1\end{array}$ & $\begin{array}{l}10 \\
4 \\
3 \\
2\end{array}$ \\
\hline & \multicolumn{9}{|c|}{$\begin{array}{c}\text { Number of steroid treated cases who turned around at various } \\
\text { intervals after start of treatment. }\end{array}$} \\
\hline & $\begin{array}{c}0-4 \\
\text { days }\end{array}$ & $\begin{array}{c}5.9 \\
\text { days }\end{array}$ & $\begin{array}{l}10-14 \\
\text { days }\end{array}$ & $\begin{array}{l}15-19 \\
\text { days }\end{array}$ & $\begin{array}{l}20-24 \\
\text { days }\end{array}$ & $\begin{array}{l}25-29 \\
\text { days }\end{array}$ & $\begin{array}{l}30-39 \\
\text { days }\end{array}$ & $\begin{array}{l}40-49 \\
\text { days }\end{array}$ & $\begin{array}{r}50+ \\
\text { days }\end{array}$ \\
\hline & 4 & 4 & 1 & 1 & 0 & 0 & 0 & 0 & 0 \\
\hline
\end{tabular}


steroid at the same interval from the time of onset; that is those who had not yet received steroids nor reached their turnaround.
Table 2 shows the comparison between the steroid treated cases and those available for steroid at the same interval from onset, divided in- to age and sex groups. The rank of the steroid treated cases, based on the remaining time to turnaround, is compared to the number of individu-

TABLE 2

Turnaround after steroid treatment compared to interval before turnaround in patients not yet given steroid. Patients grouped by age, sex and number of days after onset.

\begin{tabular}{|c|c|c|c|}
\hline Age and sex & $\begin{array}{l}\text { Number of } \\
\text { patients in } \\
\text { group }\end{array}$ & $\begin{array}{l}\text { Day of illness } \\
\text { at start of steroid in } \\
\text { treated case }\end{array}$ & $\begin{array}{l}\text { Number of days to turnaround in } \\
\text { patients available for steroid on day } \\
\text { in column } 3 \text {. (Steroid case underlined) }\end{array}$ \\
\hline $\begin{array}{c}\text { Males aged } \\
14-29\end{array}$ & 2 & 84 & $\underline{8}, 13$. \\
\hline $\begin{array}{c}\text { Males aged } \\
39-58\end{array}$ & $\begin{array}{l}4 \\
3 \\
2 \\
1\end{array}$ & $\begin{array}{c}64 \\
83 \\
84 \\
151\end{array}$ & $\begin{array}{l}\frac{1,22,38,97 .}{3,}, 19,78 . \\
\frac{2,77 .}{10 .}\end{array}$ \\
\hline $\begin{array}{l}\text { Males aged } \\
\text { over } 60\end{array}$ & $\begin{array}{l}2 \\
1\end{array}$ & $\begin{array}{c}77 \\
130\end{array}$ & $\frac{1,}{7} 60$. \\
\hline $\begin{array}{c}\text { Females aged } \\
35-59\end{array}$ & $\begin{array}{l}7 \\
5 \\
4\end{array}$ & $\begin{array}{l}24 \\
55 \\
58\end{array}$ & $\begin{array}{l}\frac{8}{6}, 15,37,40,52,73,92 . \\
6,9,21,42,61 . \\
3,18,39,58 .\end{array}$ \\
\hline
\end{tabular}

The probability of such a low sum of ranks/ni (where ni is the number of individuals available to be selected for treatment at the time the i'th selection was made):

in the case of males $\mathrm{P}=1 / 2 \times 1 / 4 \times 1 / 3 \times 1 / 2 \times 1 / 2 \times 3=0.031$

for females $P=1 / 7 \times 1 / 5 \times 1 / 4 \times 3=0.021$

TABLE 3

Turnaround after steroid treatment compared to turnaround in all cases available for treatment at the same number of days after onset.

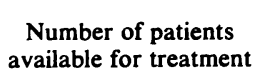

17

14

13

11

9

8

7

2

1
Day of illness when steroid was started in treated case

24

55

58

64

77

83

84

130

151
Number of days to turnaround from day in column 2, for each patient available for treatment on that day. (Steroid case underlined)

8. $15,23,35,40,41,52,54,62,68$, $73,73,78,92,113,137$.

$4,6, \underline{9}, 10,21,23,31,37,42,42$, $47,61,82,106$.

$1, \underline{3}, 7,18,20,28,34,39,39,44,58$, 79, 103.

1, 12, 14, 22, 28, 33, 33, 38, 52, 73, 97.

$\underline{1,9}, 15,20,20,25,39,60,84$.

$3,9,14,14,19,33,54,78$.

$\underline{2}, \underline{8}, 13,13,32,53,77$.

7, 31 .

10 .

Using Median test (one-tailed), $P=0.02$ that only once out of 9 selections, a value above the median was selected.

Using test based on the $331 / 3$ rd percentile (one-tailed), $P=0.003$ that only once out of 8 selections, where there were 3 or more to select from, was a value above the $331 \frac{1}{3}$ rd percentile selected. 
als in the group. It is found that the probability of randomly selecting a sum of ranks, divided by the number available, as low as that observed in this table is 0.031 for the males, 0.021 for the females.

In table 3 , each patient given steroid is compared with all patients available for steroid at that interval from onset. Using a one-tailed Median test, the probability that only once out of these nine selections a value above the median was found in a steroid case, is $p=0.02$. Using the same test based on the $331 / 3$ percentile, $p=0.003$ that only once in 8 selections was a value above the $331 / 3$ percentile chosen. When the same selections were made, calculating the interval between maximum disability and start of steroid and comparing the remaining time to turnaround with those available for steroid at the same interval after the maximum, there is still a significant effect of steroids, even though the time of maximum disability is a much less reliable date than that of onset.

It thus appears that there is sufficient evidence to conclude that the shorter times to turnaround in the steroid treated patients were due to the effect of this drug.

It is important to be certain that there was no bias towards more rapidly-recovering patients in the steroid treated group. Using a rankcorrelation method, there was no significant relation between age or sex and turnaround time, nor was there any relation between severity and turnaround, the most severely affected patients ranked 7th out of 17 and the 4 least severe ranked 1st, 4 th, 12th and 15th. In the 10 males, there was no correlation between the time from onset to maximum and that from onset to turnaround; while for some reason, in the 7 females, there was a very strong correlation. $(R s=0.964)$, but only 3 females were given steroids.

It cannot be said that cases of more rapid tempo were preferentially treated. Steroids were given after the time of maximum disability in all except one case, but the steroid treated cases as can be seen from
Table 1, did not have earlier maxima than the whole series or a shorter interval from onset to turnaround.

Table 4 shows the time to turnaround from various intervals after the onset of symptoms. This is compared to the turnaround time after corticosteroids were given. It seems clear that steroids have a significant effect in a majority of cases in hastening the turnaround. Whether the same relation holds between steroid treatment and the maximum severity of the disease cannot be ascertained from this study. Whether the total duration of disability is shortened, would be a much more difficult problem to measure and this assessment was not attempted. However, it would seem to follow that if the turnaround is accelerated, the total duration of disability is likely to be shortened. No calculation could be made of the effect of dosage or length of course given. It was a striking feature of some cases that the nerve conduction velocity measured in the distal part of the median, ulnar and peroneal nerves might still be declining following the administration of steroids, while muscle strength was improving.

Austin (1958) has suggested that administration of steroids may cause a steroid-dependent condition where the patient will relapse when the drug is withdrawn. Such a relapse occurred in three of these patients. In two, the relapse was symptomatic only and did not recur again after a further short course of corticosteroids. In the third, a serious relapse with gross limb weakness and multiple cranial nerve palsies occurred eight months after stopping the drug, but the patient began to recover again without further steroid treatment. One patient, not included in this series, was first seen after several relapses which occurred in relation to withdrawal of steroids. This patient continued to show some evidence of steroid dependency, but also developed clinical and laboratory signs indicating a diagnosis of systemic lupus erythematous.

It is suggested as a result of this study that steroid treatment is valuable in a majority of cases of sub- acute idiopathic polyneuritis. Since the median interval to turnaround is between 20 and 30 days, it is recommended that the drug be continued for at least 30 days before deciding that a response will not occur. It is recommended that corticosteroid in moderate dosage should be given to all severe cases of this disease, particularly where respiration is embarassed and should also be given in less serious cases which are not beginning to show recovery after 30 days from onset. In order to demonstrate that steroids also have an effect in the more common acute form of GuillainBarre syndrome, a controlled study with random allocation of steroid treatment would have to be undertaken.

\section{ACKNOWLEDGEMENTS}

The authors particularly express their thanks to Drs. R. T. Ross and G. Habib for referring many of the patients and to Miss Joan Edwards and Miss Lynn Stewart, Department of Physiotherapy, Manitoba Rehabilitation Hospital for the quantitative measurements of strength.

\section{REFERENCES}

SHY, G. M. and McEACHERN, D.: (1951) "Studies of the effects of Cortisone and ACTH on neurological disorders" Brain 74. 354-362.

GRAVESON, G. S.: (1957) "Acute Polyneuritis Treated With Cortisone" Lancet 1. 340-343.

HELLER, G. L. and DeJONG, R. N.: (1963) "Treatment of the Guillain-Barre Syndrome" Archives of Neurology (Chicago) 8. 179-192.

SIEGANTHALER, D. and REGLI, F.: (1966) "On the Question of Corticosteroids in Acute Polyneuropathy" Schweizerische Medizinische Wochenschrift 96. 781-787.

PRINEAS, J.: (1970) "Polyneuropathies of Undetermined Cause" Acta Neurologica Scandinavia Supp. 44.

WIEDERHOLD, W. C., MULDER, D. W., and LAMBERT, E. H.: (1964) "Polyradiculoneuropathy, A Subject Review" Mayo Clinic Proceedings, 39. 427-451.

KIMURA, J.: (1971) "An Evaluation of the Facial and Trigeminal Nerves in Polyneuropathy" Neurology 21. 745-752.

AUSTIN, J. H.: (1958) "Recurrent Polyneuropathies and Corticosteroid Treatment" Brain 81. 157-190. 